\title{
ENSO influence on La Plata Basin precipitation in the HadGEM2-ES model
}

\author{
Renata G. Tedeschi ${ }^{1, *}$, Iracema F. A. Cavalcanti ${ }^{1}$, Alice M. Grimm ${ }^{2}$ \\ ${ }^{1}$ Center for Weather Forecasting and Climate Studies/National Institute for Space Research, Cachoeira Paulista, \\ SP12630-000, Brazil \\ ${ }^{2}$ Department of Physics, Federal University of Parana, Curitiba, PR81531-980, Brazil
}

\begin{abstract}
ENSO episodes affect South American precipitation and the frequency of extreme precipitation events, mainly in the La Plata Basin (LPB). We analyzed the representation of Central and Eastern ENSO diversity in a historical simulation of the HadGEM2-ES model, and the results showed that this model does not reflect the ENSO diversity. However, the model does represent the frequency of Eastern ENSO. Therefore, we used this model to analyze the influences of this type of ENSO on precipitation and frequency of extreme precipitation events over the LPB in simulations (historical scenario) and projections (RCP8.5 scenario), during austral summer and autumn. The HadGEM2-ES model reproduced the anomalous precipitation dipole pattern (increased precipitation over southeastern South America and decreased precipitation over the north/northeast) in eastern El Niño during both seasons, and the opposite pattern in eastern La Niña during the austral autumn. The model reproduced the patterns of anomalous frequency of extreme events that occur over South America during both seasons of eastern El Niño, but failed to reproduce these patterns during eastern La Niña. The future projections showed patterns of anomalous precipitation and frequency of extreme events that were similar to those simulated for the present, but were more intense and affected a wider area.
\end{abstract}

KEY WORDS: Central and Eastern ENSO - Precipitation anomalies · Extreme precipitation events · La Plata Basin $\cdot$ El Niño $\cdot$ La Niña

\section{INTRODUCTION}

Recent studies have shown the importance of studying the influence of different types of El Niño-Southern Oscillation (ENSO) events separately (Ashok et al. 2007, Kao \& Yu 2009, Kug et al. 2009, Yeh et al. 2009, Tedeschi et al. 2013, 2015). The main sea surface temperature (SST) anomalies (SSTA) in ENSO episodes occur in the eastern equatorial Pacific or central equatorial Pacific. These different types of ENSO influence the South American precipitation in different ways. During austral summer (December-January-February, DJF) the eastern Pacific El Niño (EEN) induces precipitation increases over southeastern South America and decreases over northern/northeastern South America, while during central Pacific El Niño (CEN), precipitation decreases over southeastern, central-eastern, and central-northern South America (Li et al. 2011, Tedeschi et al. 2013, 2015). In austral autumn (March-AprilMay, MAM), EEN produces the same DJF patterns of dry conditions in the north and wet in the south, while CEN induces increased precipitation over central-eastern South America (Tedeschi et al. 2013). The precipitation anomaly patterns over South America during MAM of La Niña years are similar during the 2 types of ENSO, but normally, the patterns during La Niña in the central Pacific (CLN) are stronger than La Niña in the eastern Pacific (ELN) (Tedeschi et al. 2013, 2015). 
The frequency of central Pacific ENSO has increased in recent decades (Yeh et al. 2009, Lee \& McPhaden 2010, Na et al. 2011, Yu \& Kim 2013). Thus, it is important to know whether models can simulate the influence of different types of ENSO on global atmospheric variables, to analyze future climate projections.

The Earth System models are the most advanced tools to represent the physical processes that occur in the climate system (atmosphere, ocean, cryosphere, biosphere, and atmospheric chemistry) and the interaction among them (IPCC 2013). Taschetto et al. (2014) used 34 coupled models of Coupled Model Intercomparison Project Phase 5 (CMIP5) to assess the representation of ENSO during the historical period and in future climate projection scenarios. Results of these models were assessed in the fifth report of the IPCC (IPCC-AR5, IPCC 2013). The majority of models can reproduce the intensity and location of maximum SSTA during ENSO. Moreover, they can represent the magnitude of the asymmetry between El Niño and La Niña and the differences between 2 types of El Niño, but fail to represent the differences between the 2 types of La Niña (Taschetto et al. 2014). Steinhoff et al. (2015) showed that CMIP5 models can represent the sign of precipitation anomalies over Central America and northwestern South America during the ENSO that occurs in the eastern Pacific, and Tedeschi \& Collins (2016) showed the same results for tropical South America when they analyzed different types of ENSO, but both studies indicated that CMIP5 models have problems in simulating the magnitude of precipitation anomalies. Furthermore, Tedeschi \& Collins (2016) reported that CMIP5 models have difficulty in simulating the correct sign of precipitation anomalies during different types of ENSO in central and southeastern South America.

Cavalcanti \& Shimizu (2012) showed that the HadGEM2-ES model can simulate well the seasonal variability of precipitation, temperature, and winds over South America in the historical period (1979/ 1980-2004/2005), especially the difference between the austral winter (June-July-August, JJA) and summer (DJF). Furthermore, the model can also represent one of the main features of DJF precipitation variability, viz. the South Atlantic Convergence Zone and the Pacific-South America teleconnection.

The main objective of the present study was to evaluate the ability of HadGEM2-ES to represent the influence of ENSO on precipitation and extreme precipitation events over the La Plata Basin (LPB; $38-14^{\circ} \mathrm{S}, 6-43^{\circ} \mathrm{W}$ ) during historical simulations and future projections. In addition, the model's ability to represent 2 types of ENSO is discussed.

\section{DATA AND METHODS}

\subsection{Data}

The period of observed data and the model historical simulation is 1960-2005, and the period of future model projections is 2054-2099. The historical simulations of CMIP5 end in 2005. The observed monthly SST dataset was obtained from the Extended Reconstructed Sea Surface Temperature database (NOAA_ ERSST_V3, Smith et al. 2008), with a resolution of $1^{\circ}$ latitude $\times 1^{\circ}$ longitude. The monthly atmospheric data (horizontal wind components and specific humidity) with a grid resolution of $2.5^{\circ} \times 2.5^{\circ}$ were obtained from NCEP/NCAR reanalysis (Kalnay et al. 1996). The vertically integrated moisture flux was calculated from 1000 to $100 \mathrm{hPa}$. The daily observed precipitation from 2 different datasets (daily precipitation from stations and data of Liebmann \& Allured 2005) were interpolated in a grid with a resolution of $1^{\circ} \times 1^{\circ}$. The data of Liebmann \& Allured (2005) were only used in grid boxes where we did not have station data, and the interpolation was made by averaging the station data within circles with a radius of $0.707^{\circ}$, whose centers were separated by $1.0^{\circ}$. Monthly precipitation datsets were calculated from the monthly average of daily data.

The HadGEM2-ES is the Hadley Centre global earth system model and is part of the CMIP5 project. This model has a good representation of the atmospheric patterns and precipitation over South America, mainly the Amazon region (Cavalcanti \& Shimizu 2012). In the present study, 4 members of the HadGEM2-ES historical run (1960-2005) were used to evaluate the model's ability to represent 2 types of ENSO and the influence of eastern ENSO on South America, mainly on the LPB. Four members of the RCP8.5 scenario (2054-2099) were analyzed to verify how a climate change scenario affects this influence. The atmospheric component of the HadGEM2-ES has a grid with 192 points in latitude and 144 points in longitude $\left(1.25^{\circ} \times 1.875^{\circ}\right)$, while the oceanic component has a grid with $360 \times$ 216 points $\left(1^{\circ} \times 1^{\circ}\right.$, except between the poles and $30^{\circ}$, where the resolution increases smoothly until $1 / 3^{\circ}$ near the equator; Collins et al. 2011). The variables from the model are the same from observations, mentioned above. 


\subsection{Methodology}

\subsubsection{ENSO years}

The methodology used to determine the ENSO years was described by Tedeschi et al. (2015), and Fig. 1 shows the regions to define the type of ENSO. Positive SSTA (i.e. $>0.5^{\circ} \mathrm{C}$ ) in the East Pacific region $\left(5^{\circ} \mathrm{N}-5^{\circ} \mathrm{S}, 140^{\circ}-90^{\circ} \mathrm{W}\right)$, during at least 6 consecutive months, including October, November, and December of the beginning year of the event (year 0) and January of the following year (year +) (based on Trenberth 1997), characterizes an EEN, and negative SSTA (i.e. $<-0.5^{\circ} \mathrm{C}$ ) in the same region characterizes an ELN. When these anomalies occur in the Central Pacific region $\left(5^{\circ} \mathrm{N}-5^{\circ} \mathrm{S}, 160^{\circ} \mathrm{E}-150^{\circ} \mathrm{W}\right), \mathrm{CEN}$ or CLN is identified. If 1 year belongs to the 2 categories, the annual SSTA average is calculated in each region, and the episode is assigned to the category corresponding to the highest value. We consider that an ENSO year starts in September (year 0) and finishes in August (year +); therefore, the seasons during the ENSO years are: September-OctoberNovember in the beginning year [SON(0)], December in the beginning year and January-February in the following year $[\mathrm{D}(0) \mathrm{JF}(+)]$, March-April-May in the following year [MAM(+)] and June-July-August in the following year [JJA(+)]. In the present study, only $\mathrm{D}(0) \mathrm{JF}(+)$ and MAM(+) are analyzed.

Tedeschi et al. (2015, their Table I) showed the years when the ENSO phenomena begin in ERSST-v3 data. The same method was applied for all members of HadGEM2-ES (historical and RCP8.5 scenarios).

\subsubsection{Composites of oceanic and atmospheric fields} during ENSO

Composites of $\mathrm{D}(0) \mathrm{JA}(+)$ and $\mathrm{MAM}(+)$ anomaly fields (SST, precipitation, horizontal wind at $200 \mathrm{hPa}$, and vertically integrated moisture flux) were calculated for Eastern ENSO. The statistical significance of the composites was obtained using the test based on

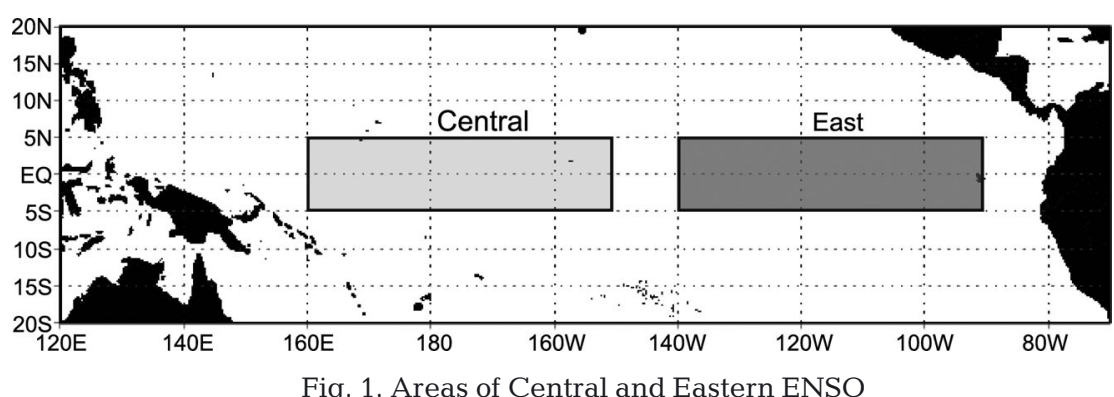

Fig. 1. Areas of Central and Eastern ENSO
Table 1. Number of years in each ENSO category. ERSST-v3 is a dataset developed by NOAA, and is described in Smith et al (2008). The historical and RCP8.5 HadGEM2-ES runs have 4 members each. The ensemble-mean number of ENSO episodes is given in parentheses. CEN (EEN): central (eastern) El Niño; CLN (ELN): central (eastern) La Niña

\begin{tabular}{|lccccc|}
\hline & CEN & EEN & CLN & ELN & Neutral \\
\hline $\begin{array}{l}\text { ERSST-v3 } \\
\text { HadGEM2-ES, } \\
\text { historical }\end{array}$ & 6 & 8 & 8 & 7 & 17 \\
$\begin{array}{l}\text { HadGEM2-ES, } \\
\text { RCP8.5 }\end{array}$ & $2(0.5)$ & $36(9)$ & $7(1.75)$ & $34(8.5)$ & $99(24.75)$ \\
& $2(0.75)$ & $26(6.5)$ & $117(29.25)$ \\
\hline
\end{tabular}

a hypergeometric distribution (Meyer 1970, Grimm et al. 1998, 2000, Grimm \& Tedeschi 2009, Tedeschi et al. 2013, 2015). The number of years in each ENSO category is presented in Table 1. The frequency of Central ENSO in the HadGEM2-ES ensemble is very low, compared to the observation. Therefore, the occurrence of few Central ENSO cases does not allow us to analyze the differences in atmospheric composites between Central and Eastern ENSO. SSTA composites were calculated for Central and Eastern ENSO, while the other atmospheric composites were calculated only for Eastern ENSO.

The CMIP5 scenario shows trends in atmospheric and oceanic data in future scenarios. Therefore, the trends were removed (using linear trends calculated between 2054 and 2099) in all grid points, for all atmospheric and oceanic data of future projections (RCP8.5 scenario), in order to avoid El Niño (La Niña) events being more concentrated at the end (beginning) of the period.

\subsubsection{Extreme precipitation events}

The methodology used to calculate extreme events of precipitation was defined by Grimm \& Tedeschi (2009). This methodology uses the $90^{\text {th }}$ percentile in a Gamma distribution as a threshold to define extreme precipitation events. After calculating the frequency of extreme precipitation events in each season and year in each category (EEN, ELN, and neutral, i.e. years that are not classified as ENSO years), the difference between each category of ENSO and the neutral category was calculated. The same hypergeometric distribution test mentioned above was applied to indicate the significance of the results. 


\section{IMPACTS OF CENTRAL AND EASTERN ENSO ON SEASONAL FIELDS}

\subsection{Frequency of events}

Table 1 presents the total number of episodes in each category, from ERSST-v3 data and the total and ensemble number of the historical and RCP8.5 projection runs. This table shows that the HadGEM2-ES model does not represent well the variability of different types of ENSO during the historical period. While the observed data include 6 (8) CEN (CLN) events, HadGEM2-ES shows only 2 (1.75) CEN (CLN), on average, during the same period. However, this model can represent the frequency of Eastern ENSO (9 [8.5] EEN [ELN], comparable to observed data of 8 [7] EEN [ELN]). Therefore, it can be used to study features over South America represented during Eastern ENSO.

Consistent with the tendency of several models to simulate only 1 type of ENSO (Ham \& Kug 2012, Kug et al. 2012, Xu et al. 2014), HadGEM-ES has the same tendency. Previous studies have shown that the frequency and persistence of Central ENSO have increased in recent years (Yeh et al. 2009, Lee \& McPhaden 2010, Yu \& Kim 2013). CMIP3 model projections for the future indicate that Central ENSO will be more frequent than Eastern ENSO (Yeh et al. 2009). However, in the present study, the HadGEM2ES model shows different results, as summarized in Table 1. The numbers of Central ENSO (El Niño or La Niña) are lower than Eastern ENSO, both in the present climate and future projections.

\subsection{SSTA fields in El Niño and La Niña}

\subsubsection{EEN and CEN}

Fig. 2 shows the SSTA composites of El Niño years. In EEN composites, the simulated patterns (Fig. 2b,e) are similar to the observed patterns (Fig. 2a,d), i.e. strong positive anomalies in the eastern Pacific and negative anomalies in the north and south Pacific (this pattern is known as the boomerang or horseshoe pattern). The projected patterns (Fig. 2c,f) are similar to the historical ones, but with weaker intensity inside the anomalous area.

The simulated SSTA composites of CEN (Fig. 2h,j) show positive SSTA in the central Pacific, consistent with ENSO-year definitions and observed patterns (Fig. 2g,i). During MAM(+), negative SSTA occur in the eastern Pacific near the South American coast, in the simulated and in the observed data, similar to El Niño Modoki (Ashok et al. 2007, Weng et al. 2007, Tedeschi et al. 2013). However, if the whole globe is analyzed, the simulated and observed patterns are very similar in EEN, while in CEN there are some differences, mainly in the North Pacific and Indian Ocean. These could be linked with the difficulty of the HadGEM2-ES in representing Central ENSO years, coherent with Table 1.

\subsubsection{ELN and CLN}

The ELN composites show the strongest negative SSTA in the eastern Pacific, in both seasons for the observed dataset and model results (Fig. 3a-f). The strongest anomalies in the eastern Pacific occur in $\mathrm{D}(0) \mathrm{JF}(+)$ in the observed data, as well as in simulations and projection patterns.

During $\mathrm{D}(0) \mathrm{JF}(+)$, the simulated patterns of SSTA in CLN reproduce the negative SSTA in the tropical Pacific and positive SSTA in the north and south Pacific. During MAM(+), negative SSTA occur in the central Pacific, around the equator, but there are more differences compared to the observation. In both seasons, the simulated cold anomalies are extended westward with respect to the observed ones. As during CEN, the model does not represent the CLN pattern well, and this also explains its difficulty in identifying different types of ENSO.

\subsection{Anomalous precipitation over South America - impacts over LPB}

\subsubsection{EEN}

Several studies have shown that precipitation over southeastern South America, including the LPB, increases during EEN (Ropelewski \& Halpert 1987, Aceituno 1988, Grimm et al. 1998, 2000, Grimm 2003, 2004). Observed, simulated, and projected patterns are shown in Fig. 4 during $\mathrm{D}(0) \mathrm{JF}(+)$ and $\operatorname{MAM}(+)$, where it is seen that the observed patterns agree with previous studies. The model reproduces the positive anomalies over LPB in EEN, but they are weaker and shifted southward when compared with observations in the 2 seasons. For example, there is a positive anomaly over Uruguay during EEN in the historical simulation during both seasons that does not occur in the observations. The model also reproduces the negative anomalies in northern South America, but the model fails in simulating the pattern 
(a) EEN - D(0)JF(+) - OBS

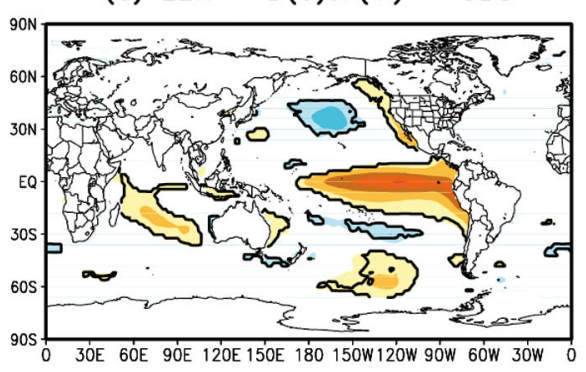

(d) EEN - MAM(+) - OBS

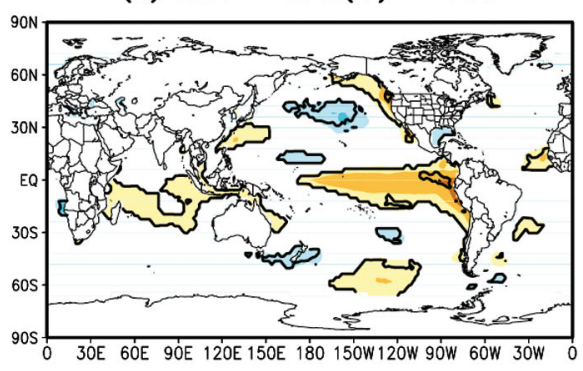

(g) CEN - D(0)JF(+) - OBS

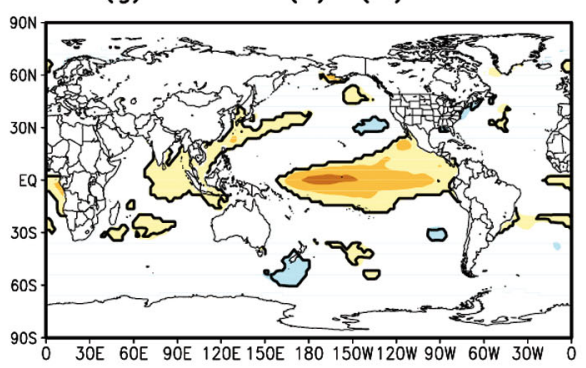

(i) $\operatorname{CEN}-\operatorname{MAM}(+)$ - OBS

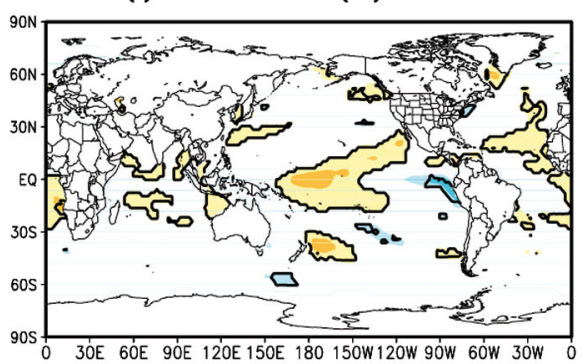

(c) EEN - D(0)JF(+) - HadGEM_rcp85

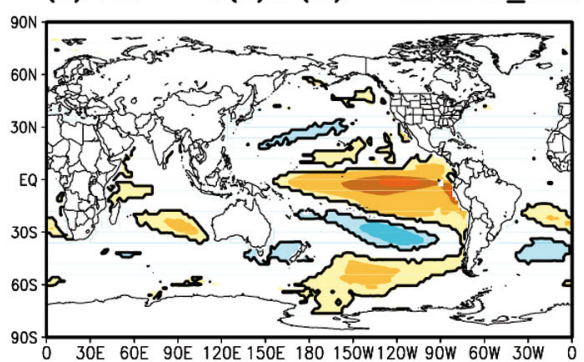

(e) EEN - MAM(+) - HadGEM_hist

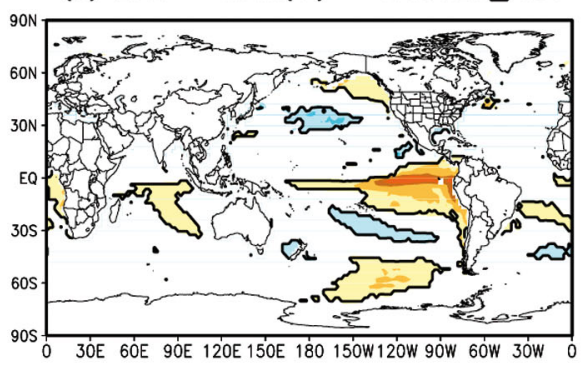

(h) CEN - D(0)JF(+) - HadGEM_hist

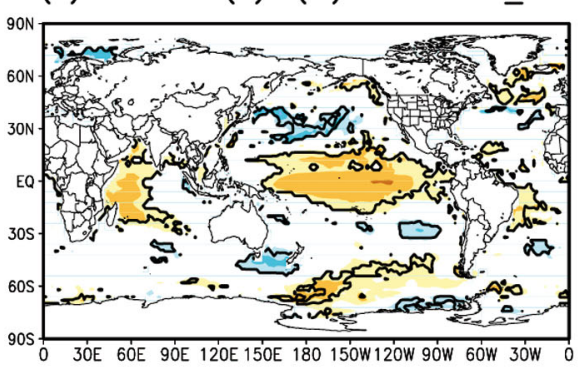

(j) CEN - MAM(+) - HodGEM_hist

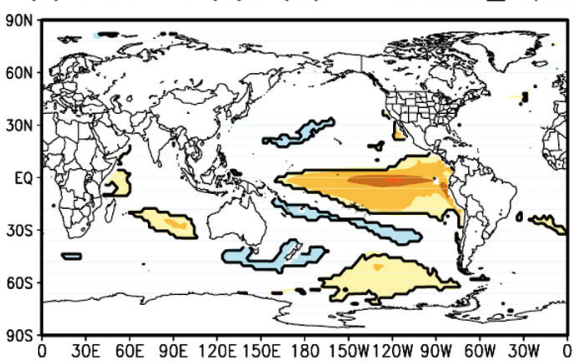

(f) EEN - MAM(+) - HadGEM_rcp85

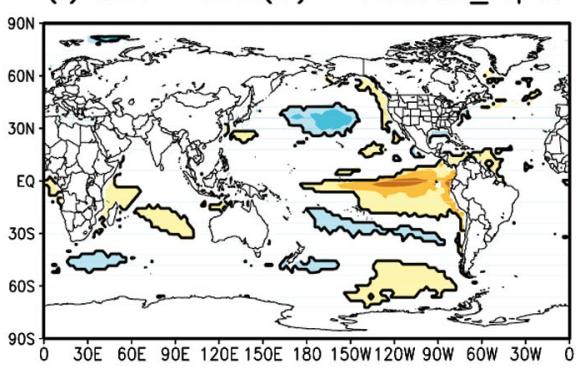

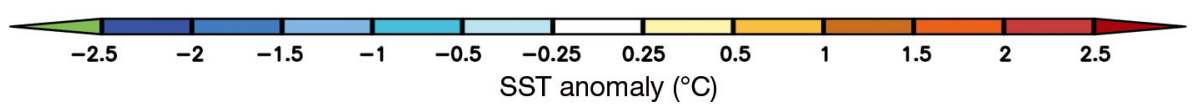

Fig. 2. Composites of SST anomalies during eastern El Niño (EEN) $[\mathrm{D}(0) \mathrm{JF}(+)(\mathrm{a}-\mathrm{c})$ and MAM(+) (d-f)] and central EN (CEN) $[\mathrm{D}(0) \mathrm{JF}(+)(\mathrm{g}, \mathrm{h})$ and MAM(+) $(\mathrm{i}, \mathrm{j})]$ based on observed data (left column), HadGEM2-ES in the historical period (center column), and HadGEM2-ES in the RCP8.5 scenario (right column). Regions with positive (negative) anomalies higher (lower) than 0.25 $(-0.25)^{\circ} \mathrm{C}$ and with a level of confidence $>90 \%$ are outlined with a thick black line

in northeastern South America during MAM(+). The future projections indicate increased precipitation over LPB during EEN events, with an even greater reduction of rainfall in the northern/northeastern parts of the continent, especially in summer (Fig. $4 \mathrm{~b}, \mathrm{c})$. This is consistent with the finding of Grimm \& Natori (2006) that in the future climate, the ENSO- related precipitation mode over South America in spring and in summer shows enhancement of the factor loadings in the northern/northeastern parts of the continent compared to the southeastern region.

The composites of observed and simulated streamline anomalies at $200 \mathrm{hPa}$ during EEN (Fig. 5) are consistent with the precipitation anomalies. The model 
(a) ELN - D(0)JF(+) - OBS

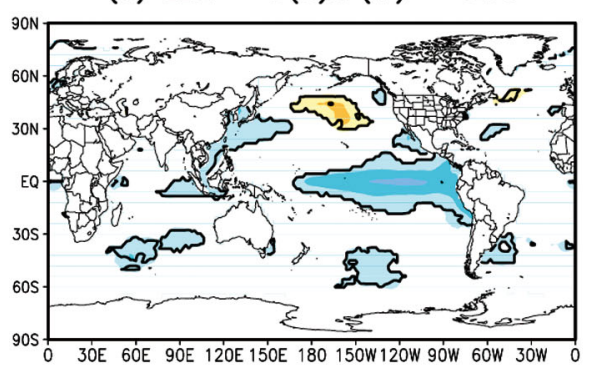

(d) $\operatorname{ELN}-\operatorname{MAM}(+)$ - OBS

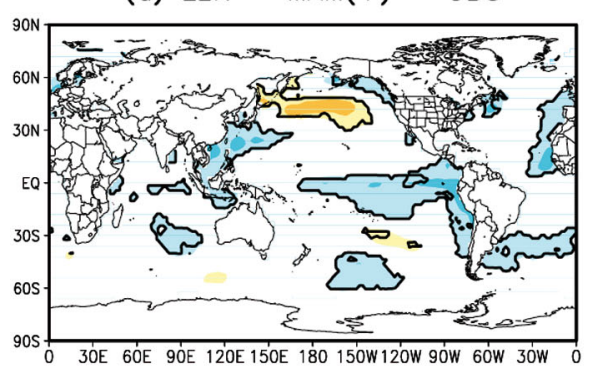

(g) $C L N-D(0) J F(+)-O B S$

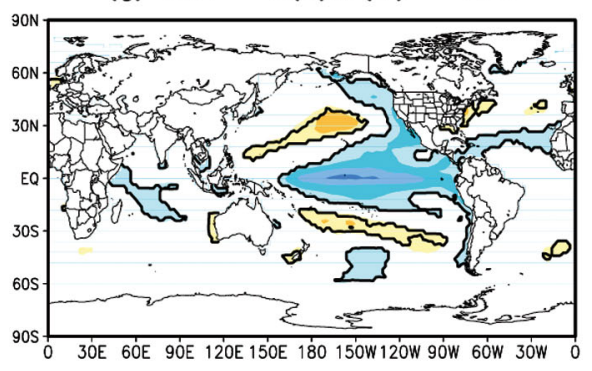

(i) $\mathrm{CLN}-\operatorname{MAM}(+)-\mathrm{OBS}$

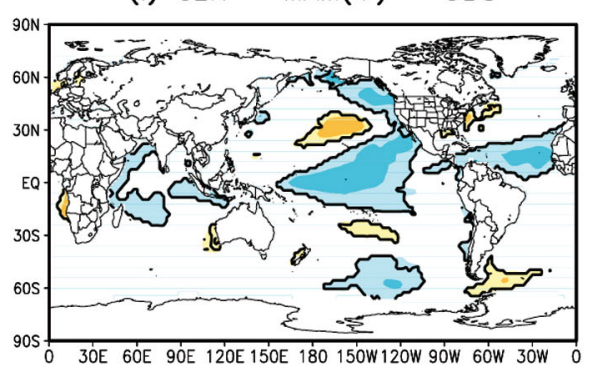

(b) ELN - D(0)JF(+) - HadGEM_hist

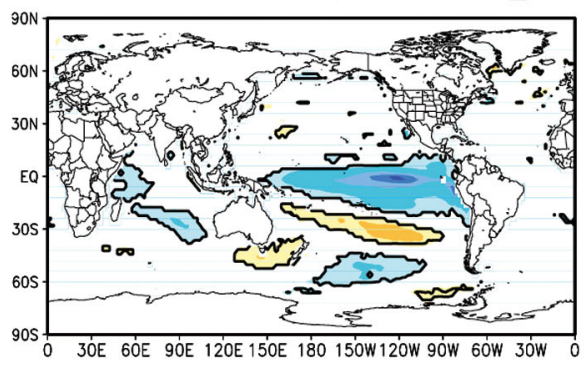

(e) $\operatorname{ELN}$ - MAM(+) - HadGEM_hist

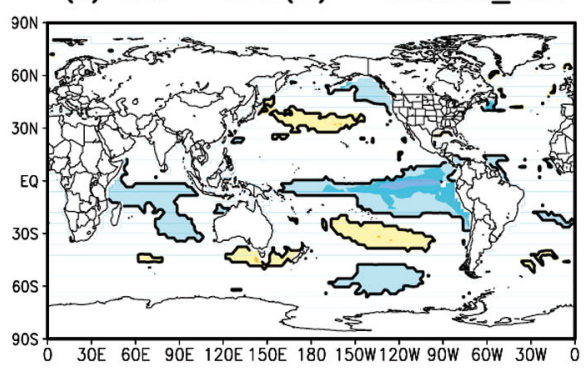

(h) CLN - D(0)JF(+) - HadGEM_hist

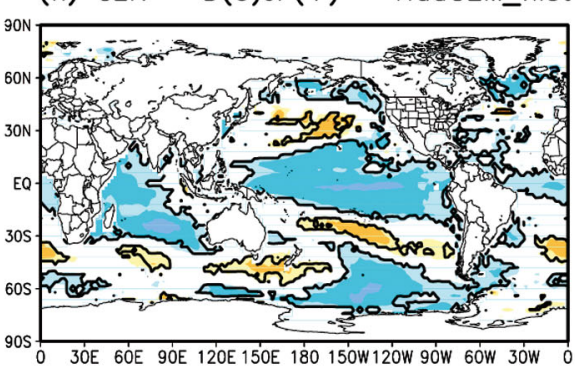

(j) CLN - MAM(+) - HadGEM_hist

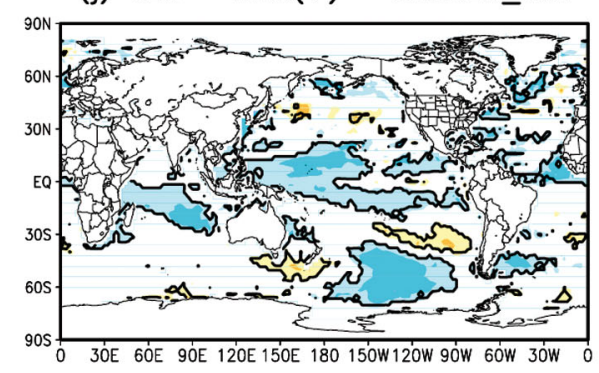

(c) ELN - D(0)JF(+) - HadGEM_rcp85

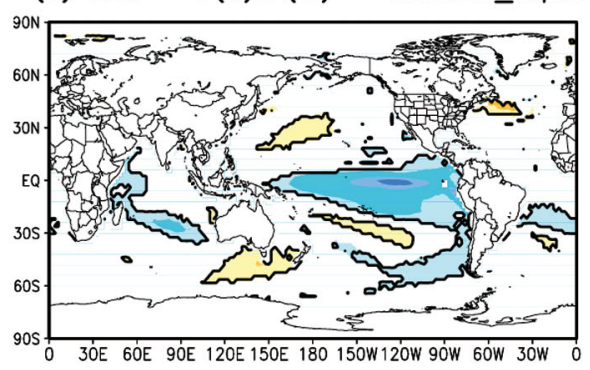

(f) $\operatorname{ELN}$ - MAM(+) - HadGEM_rcp85

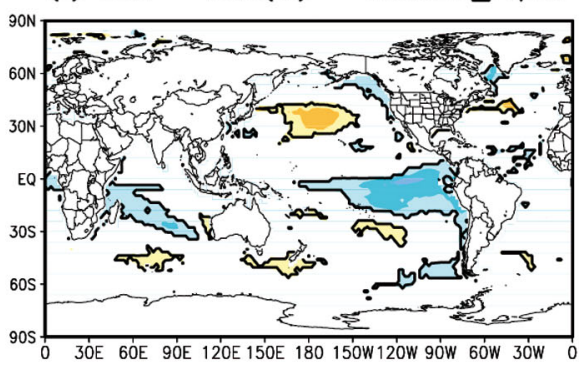

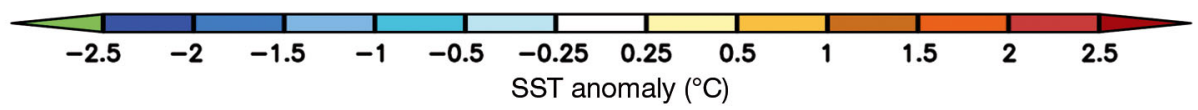

Fig. 3. Same as Fig. 2, but for La Niña years. ELN, CLN: eastern and central La Niña, respectively

represents the 2 anticyclones around the Pacific equatorial region, typical of ENSO, and the wave train tropics-extratropics that favors a pair of cyclonicanticyclonic circulation over the southwest and southeast coasts of South America. The position of these centers and the strengthening of the subtropical jet cause an increase in precipitation over LPB (Fig. 4). In MAM, the model shows the Northern Hemisphere anticyclonic center around the equator displaced eastward, and a reduction of the Southern Hemisphere anticyclonic center (approx. $15^{\circ} \mathrm{S}, 120^{\circ} \mathrm{W}$ ) in that region. Notwithstanding, the cyclonic-anticyclonic pair over southeast South America is still present and more organized in both the model and the observation, consistent with the precipitation anomalies. The projections during EEN show similar atmospheric circulation patterns favorable to precipitation anomalies, and the higher rainfall anomaly than in the his- 
(a) EEN - D(0)JF(+) - OBS

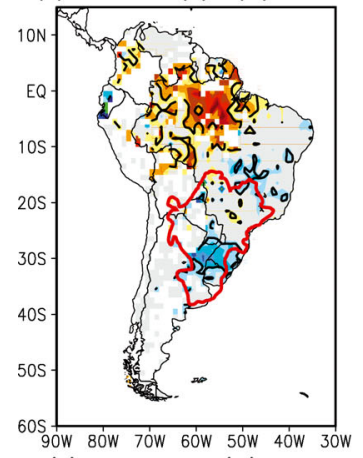

(d) EEN - MAM(+) - OBS

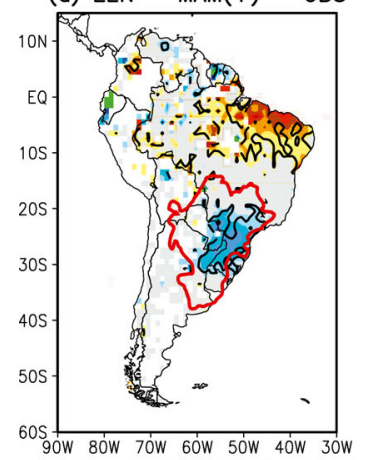

(g) $E L N-D(0) J F(+)-O B S$

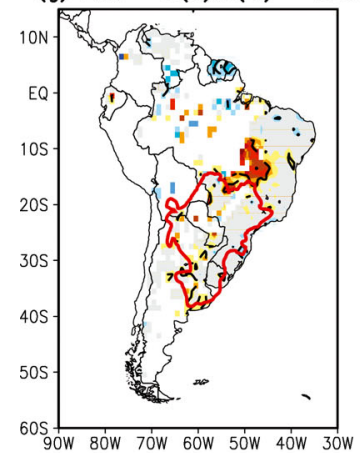

(j) $E L N-M A M(+)-O B S$

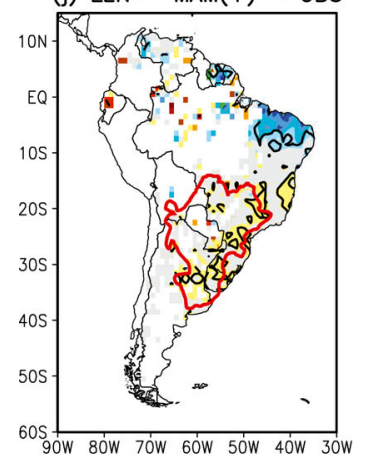

(b) EEN - D(0)JF(+) - HadGEM_hist(c) EEN - D(0)JF(+) - HadGEM_rcp85

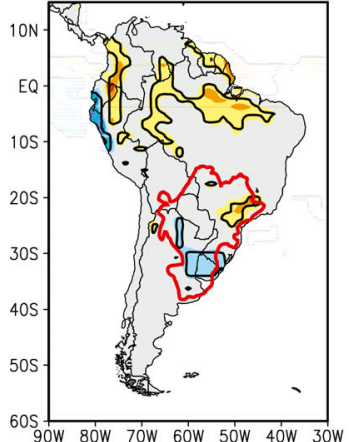

(e) EEN - MAM(+) - HadGEM_hist

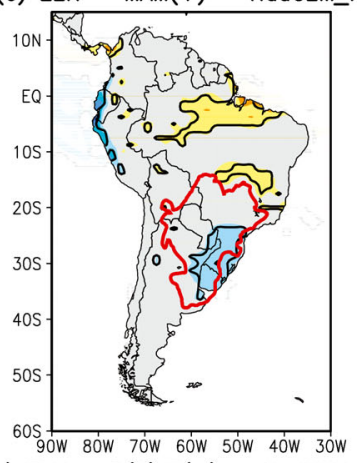

(h) ELN - D(0)JF(+) - HadGEM_hist (i) ELN - D(0)JF(+) - HadGEM_rcp85

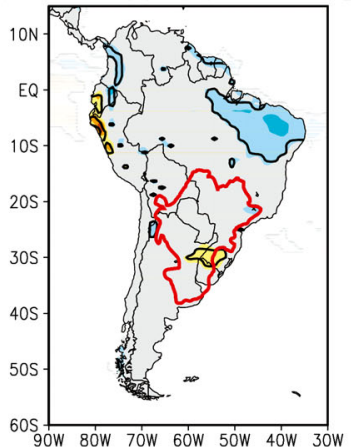

(k) ELN - MAM(+) - HadGEM_hist

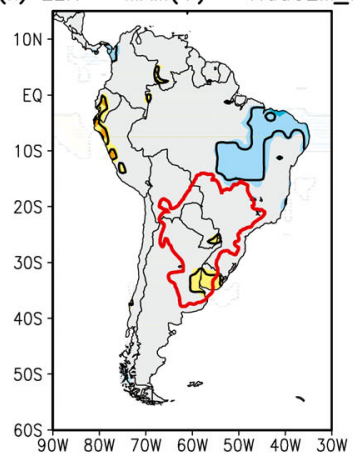

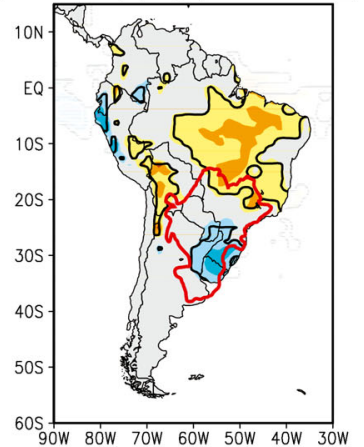

(f) $\operatorname{EEN}-\operatorname{MAM}(+)$ - HadGEM_rcp85

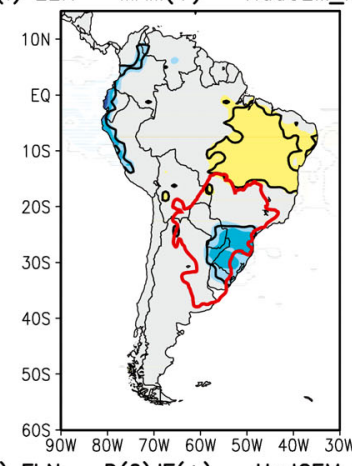

(1) ELN - MAM(+) - HadGEM_rcp85

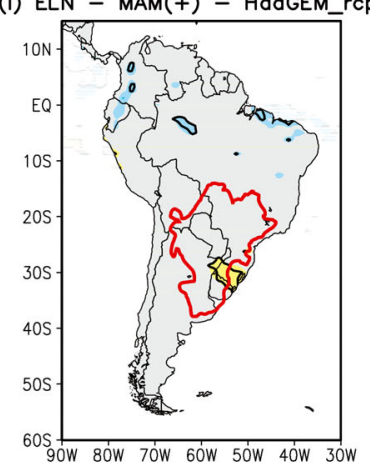

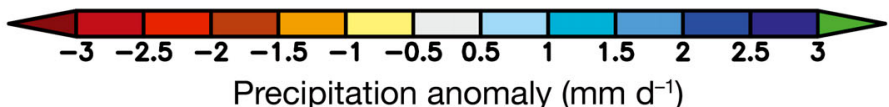

Precipitation anomaly $\left(\mathrm{mm} \mathrm{d}^{-1}\right)$

Fig. 4. Composites of precipitation anomalies $\left(\mathrm{mm} \mathrm{d}^{-1}\right)$ during eastern El Niño $(E E N)[D(0) J F(+)(a-C)$ and MAM(+) $(d-f)]$ and eastern La Niña (ELN) $[\mathrm{D}(0) \mathrm{JF}(+)(\mathrm{g}-\mathrm{i})$ and MAM(+) $(\mathrm{j}-\mathrm{l})]$ based on observed data (left column), HadGEM2-ES in the historical period (center column), and HadGEM2-ES in the RCP8.5 scenario (right column). Regions with positive (negative) anomalies higher (lower) than $0.5(-0.5) \mathrm{mm} \mathrm{d}^{-1}$ and with a level of confidence $>90 \%$ are outlined with a thick black line. The position of 
(a) EEN - D(0)JF(+) - OBS

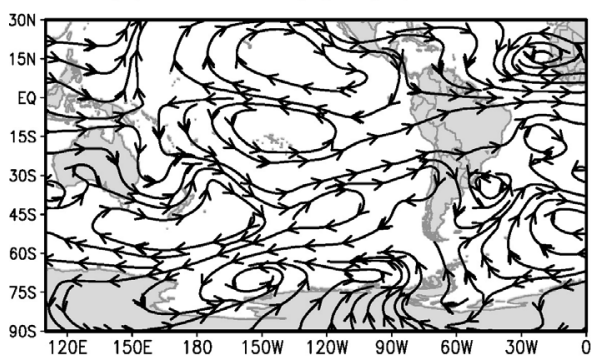

(d) EEN - MAM(+) - OBS

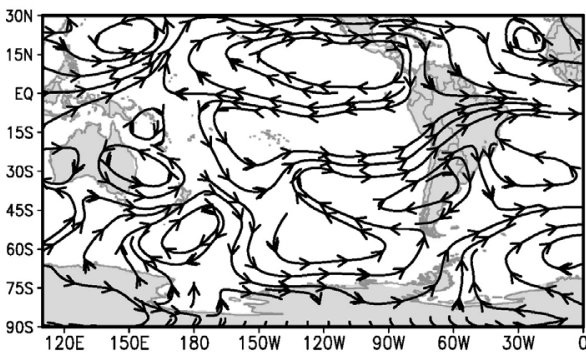

(g) ELN - D(0)JF(+) - OBS

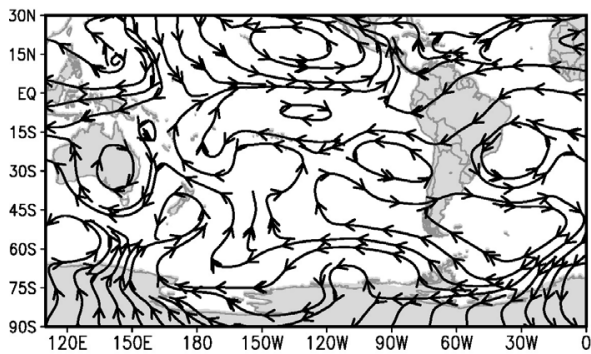

(j) ELN - MAM(+) - OBS

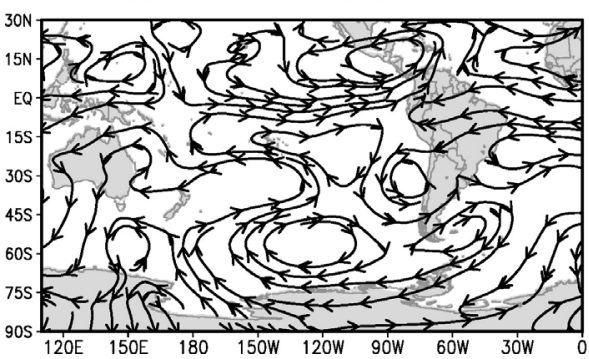

(b) EEN - D(0)JF(+) - HadGEM_hist

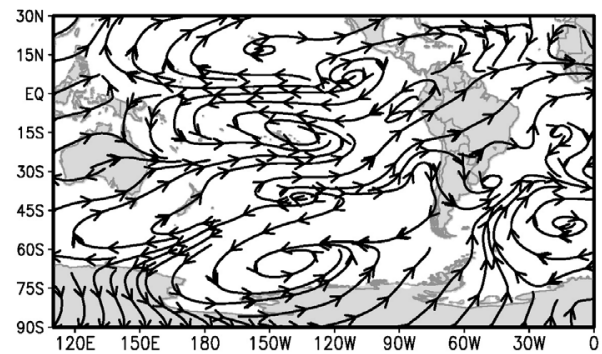

(e) EEN - MAM(+) - HadGEM_hist

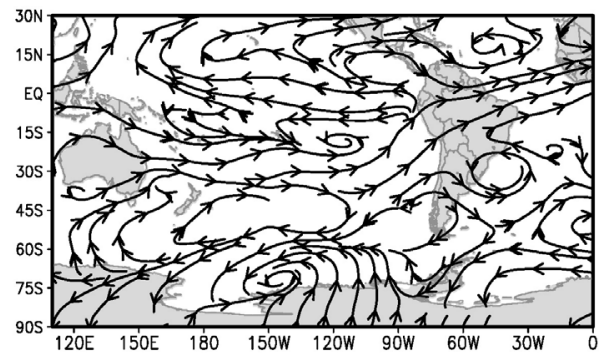

(h) ELN - D(0)JF(+) - HadGEM_hist

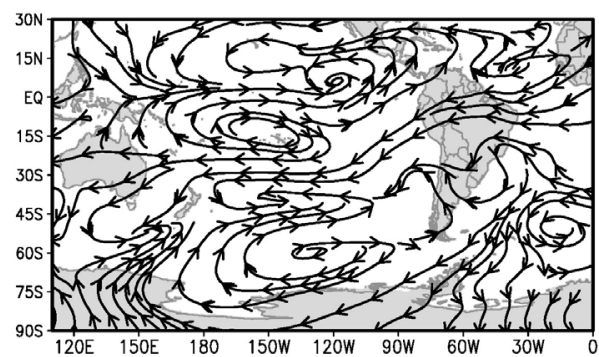

(k) ELN - MAM(+) - HadGEM hist

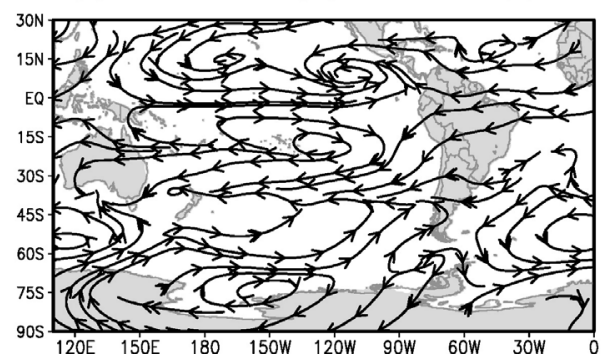

(c) EEN - D(0)JF(+) - HadGEM_rcp85

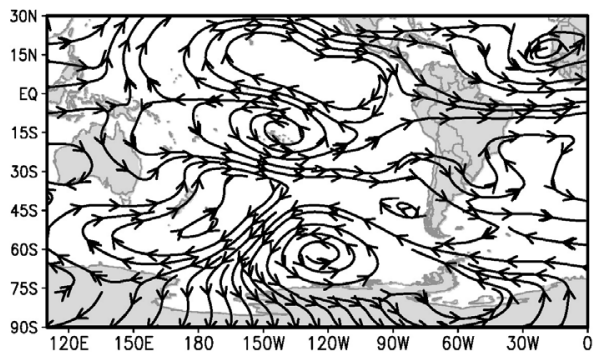

(f) EEN - MAM(+) - HadGEM_rcp85

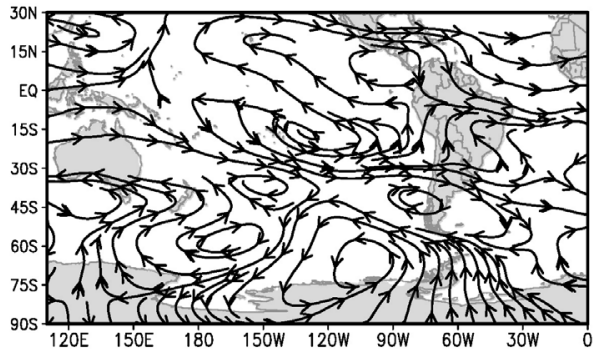

(i) ELN - D(0)JF(+) - HadGEM_rcp85

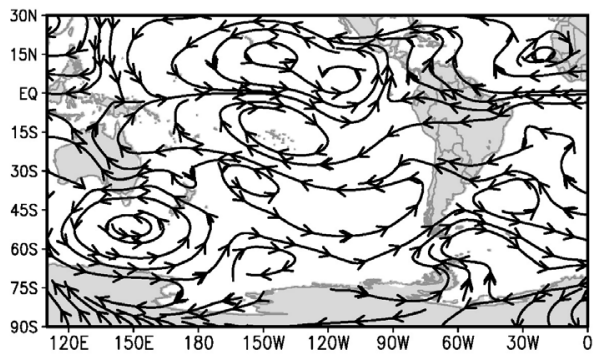

(1) ELN - MAM(+) - HadGEM_rcp85

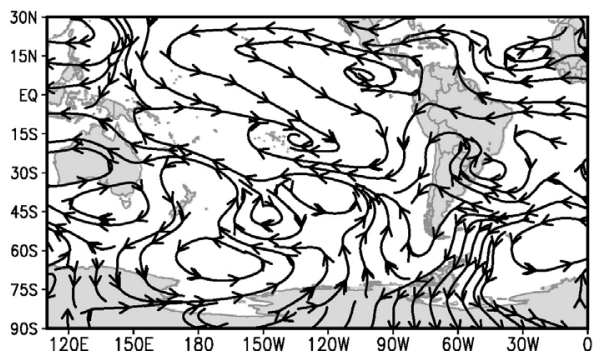

Fig. 5. Composites of streamline anomalies at $200 \mathrm{hPa}$ during eastern El Niño (EEN) [D(0)JF(+) (a-c) and MAM(+) (d-f)] and eastern La Niña (ELN) $[\mathrm{D}(0) \mathrm{JF}(+)(\mathrm{g}-\mathrm{i})$ and MAM $(+)(\mathrm{j}-\mathrm{l})]$ based on observed data (left column), HadGEM2-ES in the historical period (center column), and HadGEM2-ES in the RCP8.5 scenario (right column)

torical period is related to the increase in moisture flux in the atmosphere, as discussed below. The high level circulation changes over tropical South America result in expansion, to the south, of the area with negative precipitation anomalies (Fig. 4).
The anomalies of moisture flux in EEN (Fig. 6), in the simulation and projection, show the increase in moisture flux from the Amazon region to the southeast of the continent in both $\mathrm{D}(0) \mathrm{JF}(+)$ and $\mathrm{MAM}(+)$ in the future climate. Although weaker in the historical run

Fig. 6. Composites of anomalous vertically integrated moisture flux $\left(10^{-2} \mathrm{~kg} \mathrm{~m} \mathrm{~s}^{-1}\right)$ during eastern El Niño (EEN) $[\mathrm{D}(0) \mathrm{JF}(+)$ $(\mathrm{a}-\mathrm{C})$ and MAM $(+)(\mathrm{d}-\mathrm{f})]$ and eastern La Niña $(\mathrm{ELN})[\mathrm{D}(0) \mathrm{JF}(+)(\mathrm{g}-\mathrm{i})$ and MAM $(+)(\mathrm{j}-\mathrm{l})]$ based on observed data (left column), HadGEM2-ES in the historical period (center column), and HadGEM2-ES in the RCP8.5 scenario (right column) 
(a) EEN - D(0)JF(+) - OBS

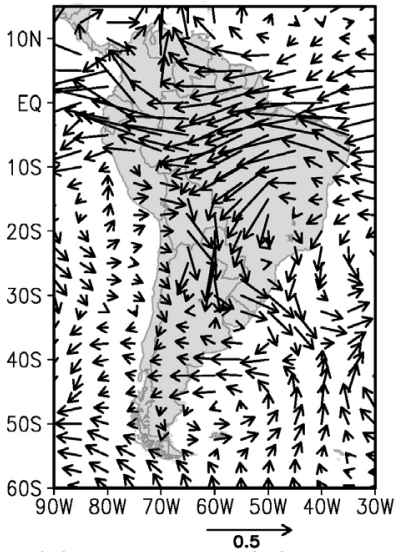

(d) EEN - MAM(+) - OBS

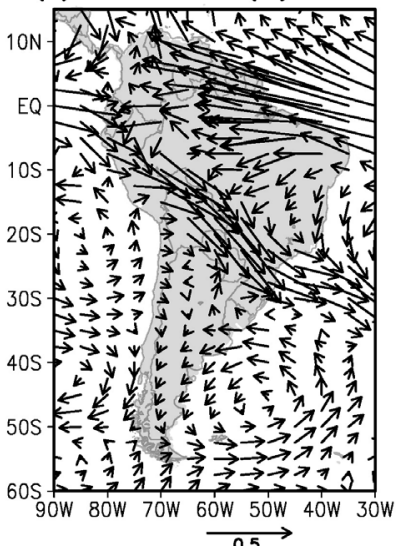

(g) ELN - D(0)JF(+) - OBS

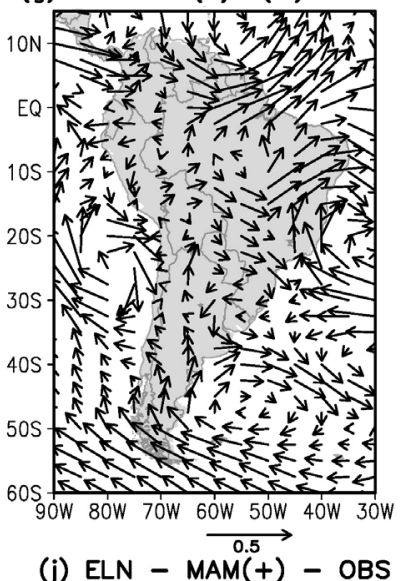

(j) $E L N-M A M(+)-O B S$

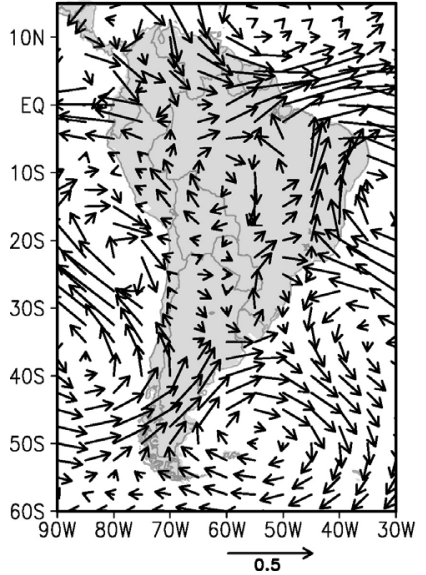

(b) EEN - D(0)JF(+) - HadGEM_hist(c) EEN - D(0)JF(+) - HadGEM_rcp85
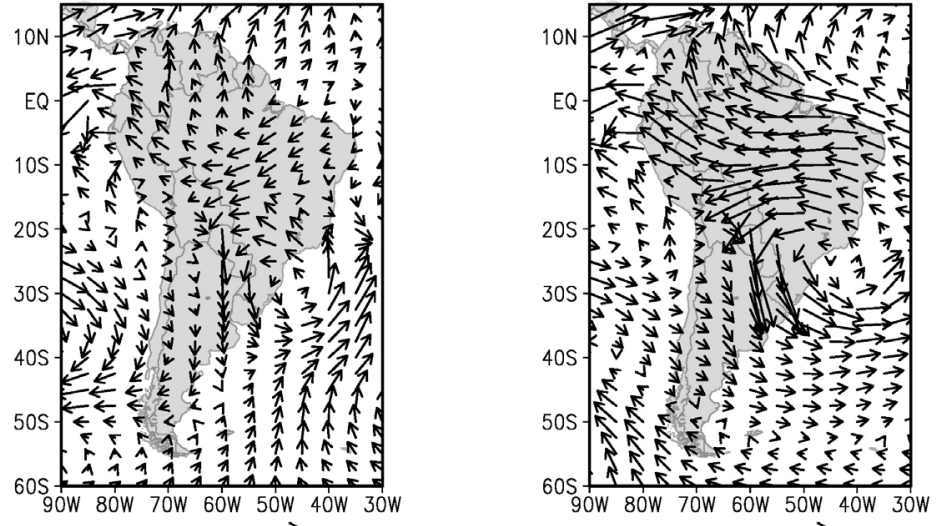

(e) EEN - MAM(+) $\stackrel{0.5}{-}$ HadGEM_hist

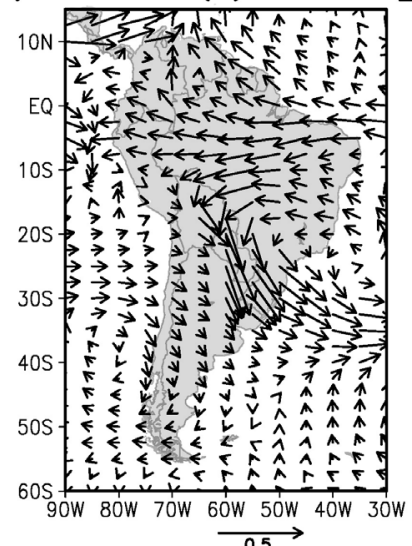

(f) EEN - MAM(+) $\stackrel{0.5}{-}$ HadGEM_rcp85

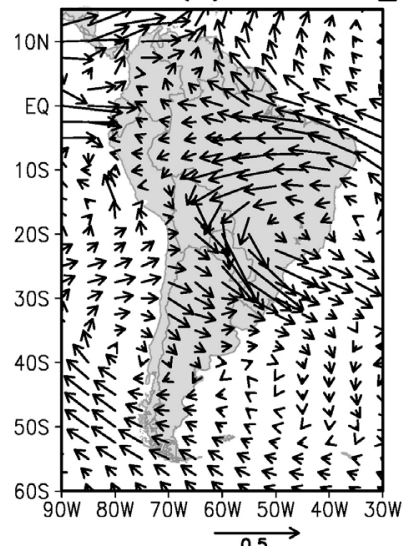

(h) ELN - D(0)JF(+) - HadGEM_hist (i) ELN $-D(0) J F(+)-$ HadGEM_rCp85

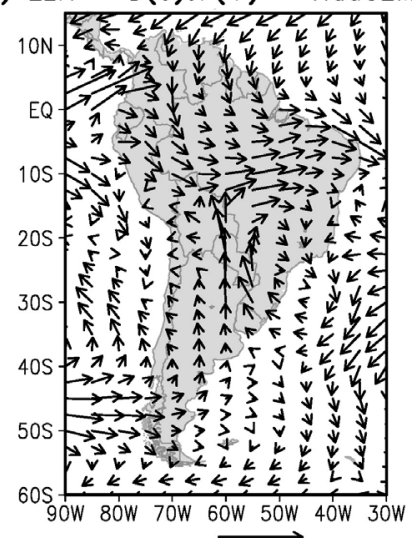

(k) ELN - MAM(+) $\stackrel{0.5}{-}$ HadGEM_hist

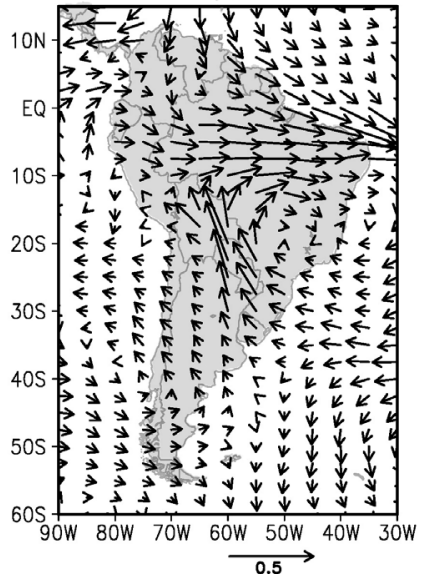

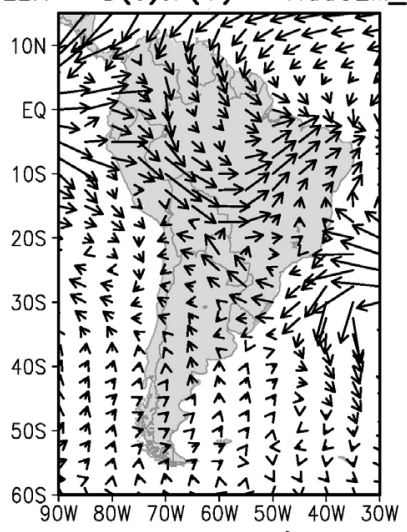

(1) ELN - MAM(+) $\stackrel{0.5 \text { HadGEM_rCp85 }}{-}$

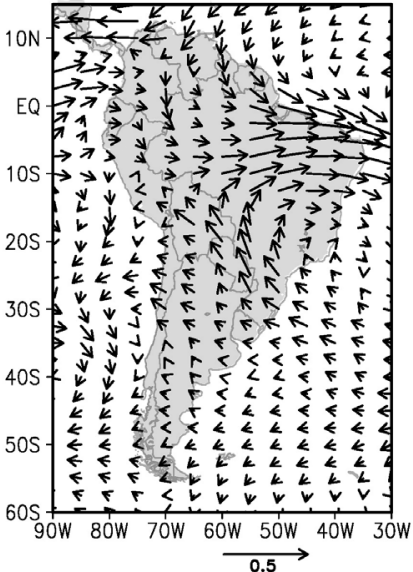


than in the observations, the model simulates this flux, which increases the precipitation over the southeast region. The increase in moisture flux southward in the future contributes to the precipitation increase over the LPB. Over the northern/northeastern parts of the continent, the moisture flux anomalies westwards also increase in the future climate.

\subsubsection{ELN}

During La Niña, negative anomalies are observed in small areas of the LPB, mainly during MAM(+) of ELN (Fig. 4j). The model indicates dry conditions over the middle/lower LPB and wet conditions over the northeast in $\mathrm{D}(0) \mathrm{JF}(+)$ and $\operatorname{MAM}(+)$. This dipole of precipitation (decrease in southeastern and increase in northeastern South America) occurs only during MAM in the observations. During this season, under a warming scenario, the model still shows dry conditions over the LPB, but the positive anomaly over northeastern South America turns to normal conditions.

The streamline anomalies display the typical pair of cyclonic circulation around the equator over the Pacific during La Niña, in both model results and observations during summer and autumn (Fig. 5g-l). The model also reproduces the easterly anomalies over tropical South America, but the 2 anticyclonic circulations over the southwestern and southeastern coasts of the continent are weakly simulated.

The anomalies of moisture flux in ELN (Fig. 6) simulated during $\mathrm{D}(0) \mathrm{JF}(+)$ and $\mathrm{MAM}(+)$ are weaker than the observed ones and show a moisture flux anomaly northwards over LPB, which explains the dry conditions in this region. This feature does not exist in observed ELN. Therefore, simulated and observed patterns have the same sign in composites of precipitation anomalies in ELN, but the mechanisms that cause the anomalies are different-in the observations, the cause is the circulation over the region, whereas in the simulation, it is associated with the simulated moisture divergence. The future projections during MAM(+) show a reduction in moisture flux towards the LPB (anomalous northward moisture flux), which is consistent with the decreased precipitation during ELN.

\section{FREQUENCY OF EXTREME EVENTS}

The maps of the differences in the frequency of extreme events between EEN and neutral years, both observed (Fig. 7a,d) and simulated by the
HadGEM2-ES model (Fig. 7b,e), show the expected pattern, viz. an increase in southeastern and a decrease in northern/northeastern South America (Grimm \& Tedeschi 2009). Notwithstanding, there are important differences between the model and observations, especially in northeastern Brazil, in MAM, where the reduced frequency of extreme events is not well simulated by the model (Fig. 7d,e). Therefore, the projection cannot be assessed for that region. Over the $\mathrm{LPB}$, the difference in the frequency of extreme events between EEN and neutral years in future projections (Fig. ${ }^{\mathrm{C}} \mathrm{C}, \mathrm{f}$ ) shows the same general features of the historical period, but more similar to the observed variations, between EEN and neutral years (Fig. 7a,d). The main difference with respect to the present climate is the strongest increase in extreme events in southeastern South America.

Fig. $7 g-1$ presents the differences between the frequency of extreme events during ELN and neutral years. The observed patterns in DJF and MAM are different. HadGEM2-ES can reproduce the anomalies in parts of northeastern Brazil (more extreme events) and in parts of the LPB (less extreme events) in $\mathrm{MAM}(+)$ during ELN. During $\mathrm{D}(0) \mathrm{JF}(+)$ of ELN, there is a strong decrease in the frequency of extreme precipitation events over northeastern South America in the observed data, while the simulated pattern shows an increase.

The differences between ELN and neutral years in the future projections are small compared to the historical period in MAM(+). As in precipitation composites, HadGEM2-ES cannot reproduce the pattern of extreme precipitation events in ELN during $\mathrm{D}(0) \mathrm{JF}(+)$. Thus, the future projection cannot be evaluated.

\section{DISCUSSION AND CONCLUSION}

The HadGEM2-ES has difficulty in reproducing Central ENSO, since it indicates an average of 2 CEN and 1.75 CLN, while 6 and 8 cases were observed, respectively. This agrees with other studies showing that coupled models have difficulty in representing different types of ENSO (Ham \& Kug 2012, Kug et al. 2012, Xu et al. 2014). In future projections, the number of central Pacific episodes is even lower, with just $0.5 \mathrm{CEN}$ and $0.75 \mathrm{CLN}$. This disagrees with results from CMIP3 models that showed an increase in the frequencies of Central ENSO in future projections (Yeh et al. 2009). Our results indicate that the HadGEM2-ES model cannot be used to study different types of ENSO following the present method- 
(a) EEN - D(0)JF(+) - OBS

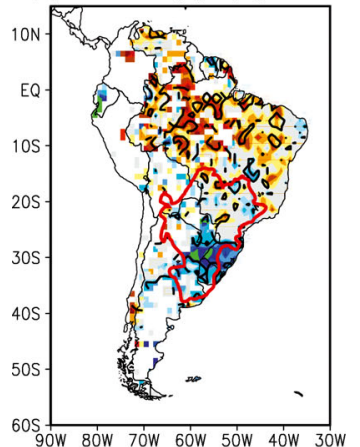

(d) EEN - MAM(+) - OBS

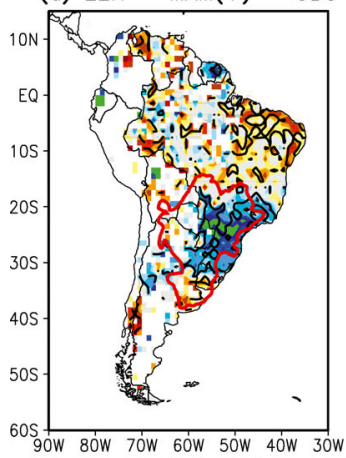

(g) $E L N-D(0) J F(+)-O B S$

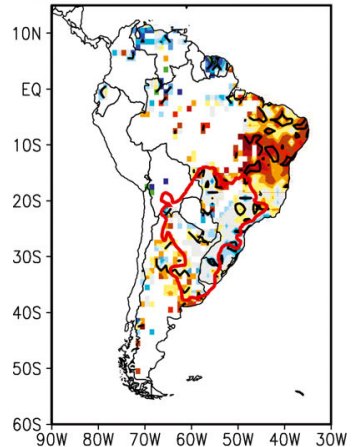

(j) $E L N-\operatorname{MAM}(+)-O B S$

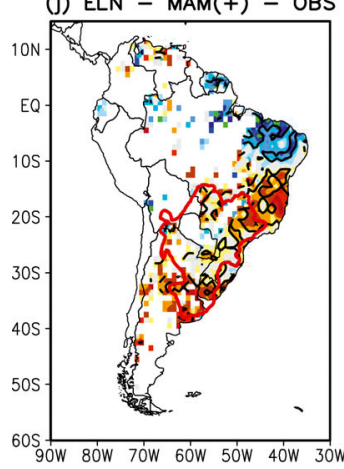

(b) EEN - D(0)JF(+) - HadGEM_hist(c)

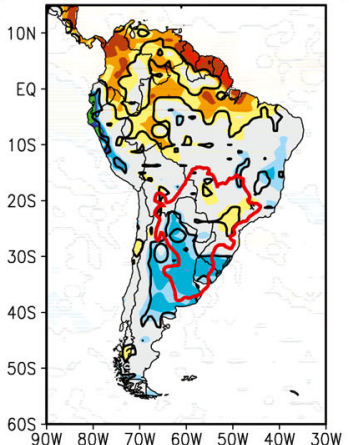

(e) EEN - MAM(+) - HadGEM_hist

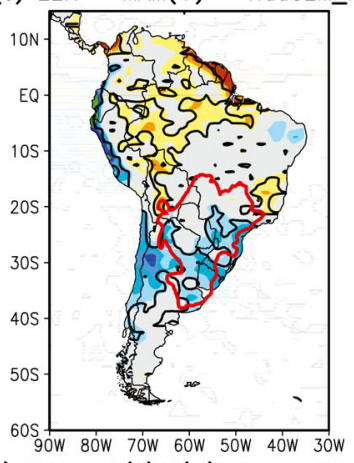

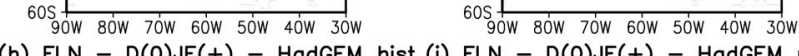

(h) ELN - D(0)JF(+) - HadGEM_hist (i) ELN - D(0)JF(+) - HadGEM_rCp85

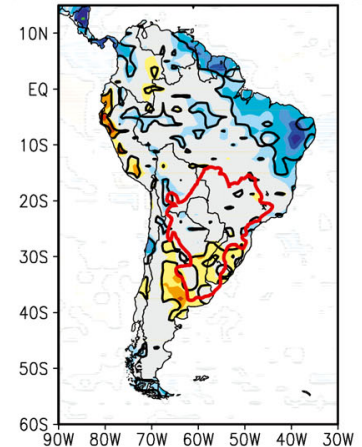

(k) $\operatorname{ELN}-\operatorname{MAM}(+)$ - HadGEM hist

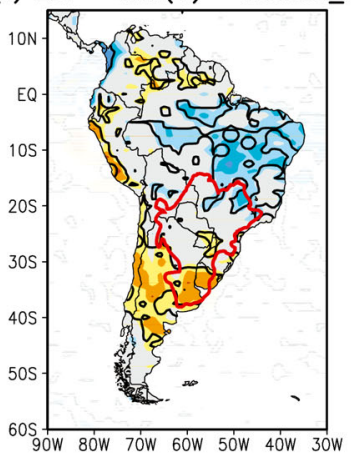

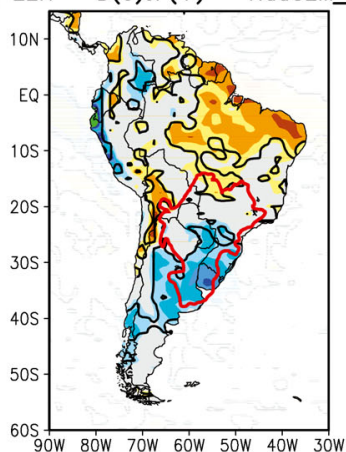

(f) EEN - MAM(+) - HadGEM_rcp85
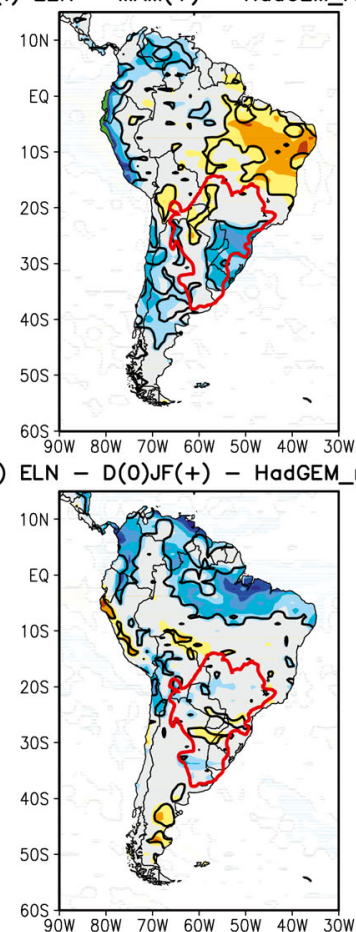

(I) ELN - MAM(+) - HadGEM_rcp85

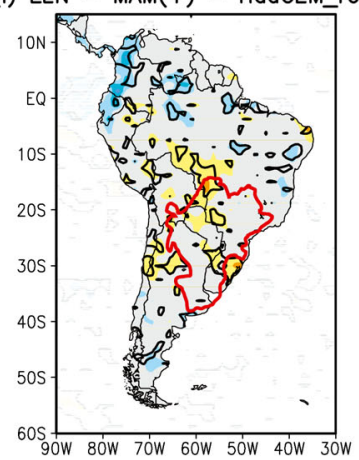

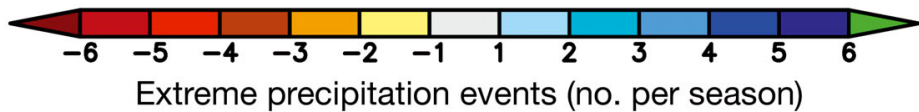

Fig. 7. Difference in the frequency of extreme precipitation events (events per season) between Eastern El Niño (EEN) and neutral years $[\mathrm{D}(0) \mathrm{JF}(+)(\mathrm{a}-\mathrm{c})$ and MAM $(+)(\mathrm{d}-\mathrm{f})]$ and between Eastern La Niña $(E L N)$ and neutral years $[D(0) J F(+)(g-i)$ and MAM(+) (j-l)] based on observed data (left column), HadGEM2-ES in the historical period (center column), and HadGEM2-ES in the RCP8.5 scenario (right column). Regions with positive (negative) anomalies higher (lower) than $1.0(-1.0)$ event $^{-1}$ and with a level of confidence $>90 \%$ are outlined with a thick black line. The position of La Plata Basin is outlined in red 
ology. However, it can reproduce the frequency of Eastern ENSO and can be used to study features of the South American precipitation during these events, in both historical simulations and in projections under a warming climate scenario. The inability of the model to reproduce Central ENSO and its impacts on South America might be related to the existence of unmodeled interdecadal climate variations, which are also responsible for interdecadal variations in model skill, even apparent in the atmospheric responses to ENSO (Grimm et al. 2006).

The patterns of SSTA were well represented in composites during Eastern ENSO in the historical simulations, but Central ENSO was well represented only in El Niño years. The simulated precipitation anomaly composites during EEN show the expected patterns for this category of years. The precipitation composites during ELN are well represented in the model only in MAM(+). In general, seasonal anomalies during La Niña were simulated less well than during El Niño.

In both seasons during EEN, precipitation anomaly patterns in the future are usually more similar to the observed patterns than those from the present climate simulation. They are more extensive and more intense in the future. On the other hand, during MAM(+) of ELN, future projections are weaker than simulated patterns. The model cannot reproduce the precipitation patterns in most areas of South America in ELN during $\mathrm{D}(0) \mathrm{JF}(+)$ and thus, these patterns cannot be analyzed in future projections.

The frequencies of extreme events over the LPB are well represented by the model during $\mathrm{D}(0) \mathrm{JF}(+)$ and MAM(+) in EEN and only during MAM(+) in ELN years. The patterns of the frequency of extreme events in projections of the future during EEN and ELN generally are similar to those simulated in the historical period, only with a greater extension and greater intensity, except for ELN during $\operatorname{MAM}(+)$.

The physical mechanisms for the precipitation anomalies over the LPB are related to the atmospheric circulation anomalies over South America and wave trains over the Pacific Ocean triggered by anomalies associated with ENSO, and are also related to the anomalous moisture flux over South America. Streamlines at $200 \mathrm{hPa}$ composites were generated to show the Rossby wave trains and their contribution to the anomalous precipitation in extratropical South America (Grimm 2003, 2004, Tedeschi et al. 2013, 2015). The model represents the wave trains during EEN, which can result in good representation of precipitation patterns over southeastern South America. However, during ELN, the compos- ites of streamline anomalies at $200 \mathrm{hPa}$ present weaker anomalies over southeastern South America, and the simulated dry conditions over the LPB are related to the reduction in moisture flux over that region. The model represents the moisture flux increase from the Amazon region towards LPB in EEN, but the simulated patterns are weaker than the observed patterns. Simulated moisture flux patterns in ELN are opposite to those in EEN, as in the observations, but there are differences between model and observations that prevent the model from reproducing the precipitation pattern in this ENSO category in DJF.

Tedeschi \& Collins (2016) studied the influence of 2 types of ENSO (Canonical and Modoki+A) on South American precipitation in different CMIP5 models. They showed that these models can represent both influences on tropical South America, but they have difficulty in representing the influences on central and southeastern South America. When we compared their results for HadGEM2-ES (figures not shown) with our results, we noted fewer cases for Modoki+A ENSO than for Central ENSO in the observed data, but the historical HadGEM2-ES simulation showed Modoki+A ENSO frequency similar to observations. In contrast, the frequency of Central ENSO (Table 1) in HadGEM2-ES results is lower than in the observed data. However, SSTA and precipitation anomaly patterns in these 2 different definitions of ENSO are similar, but during Canonical and Modoki+A ENSO, the magnitude is larger than during Eastern and Central ENSO. As in this study, HadGEM2-ES revealed precipitation patterns during Canonical and Modoki+A ENSO stronger in the future than in the present. Thus, if we change the methodology to define different types of ENSO years, the patterns may show small differences when applying one or the other methodology, but both methodologies show a strengthening in the future patterns.

Acknowledgements. R.G.T. acknowledges CAPES and CNPq (Brazilian National Council for Scientific and Technological Development) for a scholarship. We thank CNPq-Brazil for support, and A.M.G. also acknowledges a grant from the Inter-American Institute for Global Change Research (IAI) CRN3035, which is supported by the US National Science Foundation (Grant GEO-1128040). We are also grateful to the European Community's Seventh Framework Programme (FP7/2007-2013), under Grant Agreement No. 212492 (CLARIS LPB: A Europe-South America Network for Climate Change Assessment and Impact Studies in La Plata Basin). NOAA_ERSST_V3 data and NCEP reanalysis data were provided by the NOAA/OAR/ESRL PSD, Boulder, Colorado, USA, from their web site at www.esrl.noaa.gov/psd/. 


\section{LITERATURE CITED}

Aceituno P (1988) On the functioning of the Southern Oscillation in the South American sector. I. Surface climate. Mon Weather Rev 116:505-524

Ashok K, Behera SK, Rao SA, Weng H, Yamagata T (2007) El Niño Modoki and its possible teleconnection. J Geophys Res 112:C11007, doi:10.1029/2006JC003798

Cavalcanti IFA, Shimizu MH (2012) Climate fields over South America and variability of SACZ and PSA in HadGEM2-ES. Am J Clim Change 1:132-144

> Collins WJ, Bellouin N, Doutriaux-Boucher M, Gedney N and others (2011) Development and evaluation of an earth-system model-HadGEM2. Geosci Model Dev 4: 997-1062

- Dewitte B, Cuervo JV, Goubanova K, Illig S and others (2012) Change in El Niño flavours over 1958-2008: implications for the long-term trend of the upwelling off Peru. Deep-Sea Res II 77-80:143-156

> Grimm AM (2003) The El Niño impact on summer monsoon in Brazil: regional processes versus remote influences. J Clim 16:263-280

- Grimm AM (2004) How do La Niña events disturb the summer monsoon system in Brazil? Clim Dyn 22:123-138

> Grimm AM, Natori AA (2006) Climate change and interannual variability of precipitation in South America. Geophys Res Lett 33:L19706, doi:10.1029/2006GL026821

> Grimm AM, Tedeschi RG (2009) ENSO and extreme rainfall events in South America. J Clim 22:1589-1609

> Grimm AM, Ferraz SET, Gomes J (1998) Precipitation anomalies in southern Brazil associated with El Niño and La Niña events. J Clim 11:2863-2880

> Grimm AM, Barros VR, Doyle ME (2000) Climate variability in southern South America associated with El Niño and La Niña events. J Clim 13:35-58

- Grimm AM, Sahai AK, Ropelewski CF (2006) Interdecadal variations in AGCM simulation skills. J Clim 19:3406-3419

> Ham YG, Kug JS (2012) How well do current climate models simulate two types of El Niño? Clim Dyn 39:383-398

> Hill KJ, Taschetto AS, England MH (2009) South American rainfall impacts associated with inter-El Niño variations. Geophys Res Lett 36:L19702, doi:10.1029/2009GL040164

> Hill KJ, Taschetto AS, England MH (2011) Sensitivity of South American summer rainfall to tropical Pacific Ocean SST anomalies. Geophys Res Lett 38:L01701, doi: 10.1029/2010GL045571

IPCC (2013) Climate Change 2013: the physical science basis. Working Group I Contribution to the Fifth Assessment Report of the Intergovernmental Panel on Climate Change. Cambridge University Press, Cambridge

Kalnay E, Kanamitsu M, Kistler R, Collins W and others (1996) The NCEP/NCAR 40-year reanalysis project. Bull Am Meteorol Soc 77:437-471

Kao H, Yu J (2009) Contrasting eastern-Pacific and centralPacific types of ENSO. J Clim 22:615-632

> Kug JS, Jin FF, An SA (2009) Two types El Niño events: cold tongue El Niño and warm pool El Niño. J Clim 22: 1499-1515

Kug JS, Choi J, An SA, Jin FF (2010) Warm pool and cold tongue El Niño events as simulated by the GFDL 2.1 coupled GCM. J Clim 23:1226-1239

Kug JS, Ham YG, Lee JY, Jin FF (2012) Improved simulation of two types of El Niño in CMIP5 models. Environ Res Lett 7:034002

> Larkin NK, Harrison DE (2005) Global seasonal temperature and precipitation anomalies during El Niño autumn and winter. Geophys Res Lett 32:L16705, doi:10.1029/2005 GL022860

Lee T, McPhaden MJ (2010) Increasing intensity of El Niño in the central-equatorial Pacific. Geophys Res Lett 37: L14603

Li W, Zhang P, Ye J, Li L, Baker PA (2011) Impact of two different types of El Niño events on the Amazon climate and ecosystem productivity. J Plant Ecol 4:91-99

Liebmann B, Allured D (2005) Daily precipitation grids for South America. Bull Am Meteorol Soc 86:1567-1570

Meyer PL (1970) Introductory probability and statistical applications. Addison-Wesley, Reading

> Na H, Jang BG, Choi WM, Kim KY (2011) Statistical simulations of the future 50-year statistics of cold-tongue El Niño and warm-pool El Niño. Asia-Pac J Atmos Sci 47: 223-233

- Ropelewski CF, Halpert MS (1987) Global and regional scale precipitation patterns associated with the El Niño-Southern Oscillation. Mon Weather Rev 115: 1606-1626

> Smith TM, Reynolds RW, Peterson TC, Lawrimore J (2008) Improvements to NOAA's historical merged land-ocean surface temperature analysis (1880-2006). J Clim 21: 2283-2296

Steinhoff DF, Monagham A, Clark MP (2015) Projected impact of twenty-first century ENSO changes on rainfall over Central America and northwest South America from CMIP5 AOGCMs. Clim Dyn 44:1329-1349

Taschetto A, Sen Gupta A, Jourdain N, Santoso A, Ummenhofer C, England M (2014) Cold tongue and warm pool ENSO events in CMIP5: mean state and future projections. J Clim 27:2861-2885

Tedeschi RG, Collins M (2016) The influence of ENSO on South American precipitation during austral summer and autumn in observations and models. Int J Climatol 36: 618-635

> Tedeschi RG, Cavalcanti IFA, Grimm AM (2013) Influences of two types of ENSO on South American precipitation. Int J Climatol 33:1382-1400

> Tedeschi RG, Grimm AM, Cavalcanti IFA (2015) Influence of Central and East ENSO on extreme events of precipitation in South America during austral spring and summer. Int J Climatol 35:2045-2064

> Trenberth KE (1997) The definition of El Niño. Bull Am Meteorol Soc 78:2771-2777

Trenberth KE, Caron JM, Stepaniak DP, Worley S (2002) Evolution of El Niño-Southern Oscillation and global atmospheric surface temperatures. J Geophys Res 107 : 4065, doi:10.1029/2000JD000298

Weng H, Ashok K, Behera SK, Rao SA, Yamagata T (2007) Impacts of recent El Niño Modoki on dry/wet conditions in the Pacific rim during boreal summer. Clim Dyn 29: 113-129

> Weng H, Behera SK, Yamagata T (2009) Anomalous winter climate conditions in the Pacific rim during recent El Niño Modoki and El Niño events. Clim Dyn 32:663-674

> Xu K, Su JZ, Zhu CW (2014) The natural oscillation of two types of ENSO events based on analyses of CMIP5 model control runs. Adv Atmos Sci 31:801-813

> Yeh SW, Kug JS, Dewitte B, Kwon MH, Kirtman BP, Jin FF (2009) El Niño in a changing climate. Nature 461: 511-514

Yu JY, Kim ST (2013) Identifying the types of major El Niño since 1870. Int J Climatol 33:2105-2112 